\title{
Application of DSC for Emulsified System Characterization
}

\author{
C. Dalmazzone ${ }^{1}$, C. Noïk ${ }^{1}$ and D. Clausse ${ }^{2}$ \\ 1 Institut français du pétrole, IFP, 1-4 avenue Bois-Préau, 92852 Rueil-Malmaison - France \\ 2 Université de Technologie de Compiègne, Laboratoire Génie des Procédés Industriels, 60205 Compiègne - France \\ e-mail: christine.dalmazzone@ifp.fr - christine.noik@ifp.fr - daniele.clausse@utc.fr
}

\begin{abstract}
Résumé - Applications de la DSC pour la caractérisation des systèmes émulsifiés - Cet article décrit comment l'analyse calorimétrique différentielle (DSC) peut être utilisée pour caractériser les émulsions, en particulier les émulsions eau-dans-huile opaques et concentrées rencontrées dans l'industrie pétrolière. Après une présentation de la technique, nous expliquerons comment il est possible, à partir d'un simple test réalisé sur un échantillon d'émulsion non dilué, d'obtenir des informations sur les propriétés de solidification et de fusion de ces systèmes complexes, notamment le type d'émulsion, la quantité d'eau, la présence de soluté, la stabilité et même la taille des gouttes. Quelques exemples d'applications sont donnés, en particulier sur les émulsions de champ rencontrées en production et sur les boues de forage à base d'huile.
\end{abstract}

\begin{abstract}
Application of DSC for Emulsified System Characterization - This paper will describe how Differential Scanning Calorimetry (DSC) may be used to characterize emulsions, especially the concentrated and opaque water-in-oil emulsions encountered in the oil industry. After a presentation of the technique, we will point out how it is possible, from a single test performed on an emulsion sample without dilution, to get information about the solidification and melting properties of these complex fluids, the emulsion type, the amount of water, the presence of solute, the stability and even the droplet size. Some examples of applications are given concerning oilfield emulsions and oil-based mud systems.
\end{abstract}




\section{INTRODUCTION}

Emulsions encountered in the petroleum industry are generally complex opaque and concentrated water-in-oil emulsions. These emulsions may be encountered at all stages in the petroleum recovery and processing industry: drilling fluids, production, process plant, transportation, etc. [1], and they are also a major issue in the treatment of accidental oil spills [2].

Emulsion stability may be characterized by different techniques which are generally based on the analysis of the droplets size distribution. Most of these techniques may be easily used for analyzing diluted oil-in-water emulsions (light scattering, Coulter Counter, optical microscopy, etc.), but they are unfortunately not adaptable to opaque water-in-oil emulsions. That is the reason why a rapid way to assess the stability of opaque and concentrated emulsions is still the "bottle test", which consists in monitoring the extent of phase separation with time. This test provides a significant amount of information relating to both the emulsion stability and the clarity of the separated water, but it remains empirical [3].

The major difficulty while analyzing concentrated and opaque $\mathrm{W} / \mathrm{O}$ emulsions is due to the dilution of the sample. In fact, it may create perturbation on the surface properties of the droplets and on interactions between the droplets, inducing flocculation or even coalescence phenomena. In this paper, we propose to use DSC (Differential Scanning Calorimetry), a technique based on the properties of solidification and melting of the droplets and the continuous phase of emulsions in order to characterize complex W/O emulsions from the oil industry. The objective is to describe how it is possible to get easily information about:

- the emulsion type: simple (W/O or $\mathrm{O} / \mathrm{W}$ ) or multiple (W/O/W or $\mathrm{O} / \mathrm{W} / \mathrm{O})$;

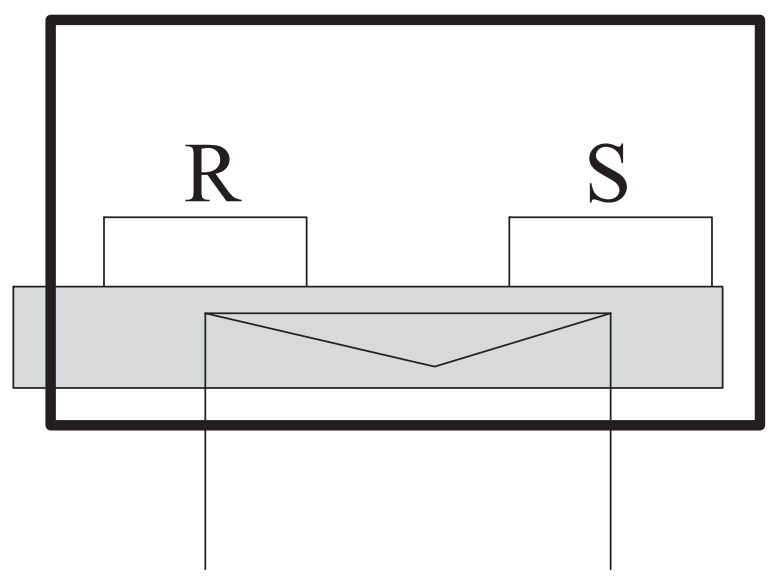

Figure 1

Section of a plate DSC (R: Reference; S: Sample).
- the amount of water and its state: bound or dispersed or in bulk;

- the compositions of the dispersed and bulk phases;

- the evolution of the droplet size.

\section{PRINCIPLE OF DSC}

Differential Scanning Calorimetry (DSC) is one of the most commonly used technique of thermal characterization of physico-chemical transformations. It consists in monitoring the heat exchanges between the sample and a reference either versus time at constant temperature, or versus temperature during a heating or cooling program. Several types of DSC have been designed, and many apparatus are commercially available.

As shown in Figure 1, the sample and the reference are contained in identical crucibles, which can be opened to atmosphere or sealed, depending on the experimental conditions required. Both crucibles are placed in a thermo-regulated furnace which imposes the temperature program. The variety of devices mainly differ by the way thermal exchanges are measured. In the most simple heat flux DSCs, a thermocouple is used to measure the temperature difference between the two crucibles at one point of their walls (generally the bottom). The heat exchange rate is derived from this temperature difference by calibration. In power compensated DSCs, the sample and the reference materials are held in a separate furnace, with its own heater element. The amount of power required to maintain the system in equilibrium conditions is directly proportional to the energy changes occurring in the sample.

The more complex DSC devices use the Calvet principle to measure very precisely the heat exchanges. The two cylindrical crucibles are placed into two independent heat sensors, formed of a great number of thermocouples surrounding the crucible. A section of one of these sensors is shown in Figure 2. Each thermocouple measures the temperature difference between the crucible and the furnace, in the radial direction. This temperature difference can be related to the local heat flow exchanged between the crucible and the furnace by:

$$
e_{i}=\frac{\varepsilon}{\lambda} \frac{d q_{i}}{d t}
$$

where $e_{i}$ is the electrical force delivered by the couple $i, \varepsilon$ its thermo-electrical constant, and $\lambda$ the thermal conductivity of the sensor material. All the couples are connected so that the sensor delivers a total electrical force $E$ related to the overall heat exchange rate $d q / d t$ by:

$$
E=\sum_{i} e_{i}=\sum_{i} \frac{\varepsilon}{\lambda} \frac{d q_{i}}{d t}=\frac{\varepsilon}{\lambda} \sum_{i} \frac{d q_{i}}{d t}=\frac{\varepsilon}{\lambda} \frac{d q}{d t}
$$


The differential measurement is achieved by connecting the reference and sample sensors in opposition. The exact relation between the heat flow and the electric power recorded is obtained by calibration.

The peak area of the recorded signal (generally called "thermogram") leads to the heat exchange during the thermal phenomenon. The fundamental equation of DSC is the following [4]:

$$
\frac{d h}{d t}=-\frac{d q}{d t}+\left(C_{S}-C_{R}\right) \dot{T}_{p}-R C_{s} \frac{d^{2} q}{d t^{2}}
$$

with:

- $d h / d t$, the heat generated by solidification $(>0)$ or absorbed by melting $(<0)$ of the sample per unit time;

- $d q / d t$, the difference of energies exchanged between the sample and the reference cells and the cell holders in order to compensate the temperatures difference between the sample and the reference;

$-\dot{T}_{p}=\frac{d T_{p}}{d t}$, the scanning rate, a positive constant during

Hence, $d h / d t$ is the result of the sum of three terms: the first being given by the signal measured from the zero line, the second being the baseline displacement due to the difference in heat capacity between the sample and the reference and the third being the slope of the recorded signal multiplied by the product $R C_{s}, R$ being the thermal resistance between the cell and the heater.

The base line is the thermogram obtained in absence of any thermal phenomenon. The form of the base line depends on the evolution of the sample heat capacity. The energy of a thermal phenomenon is measured by the surface

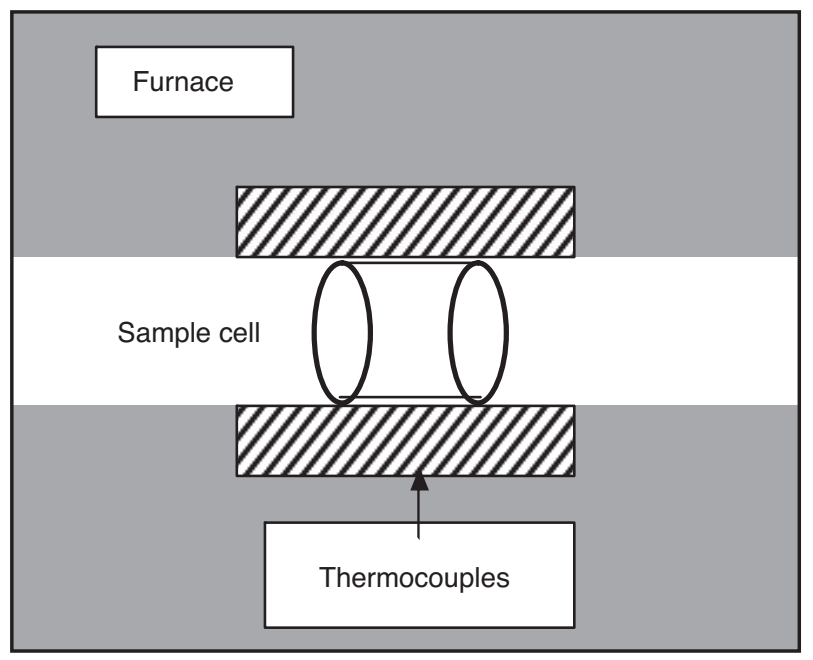

Figure 2

Section of a Calvet type DSC showing one of the two sensors. area of the corresponding peak. The study of the melting of pure compounds, for which the melting enthalpies are known, allows a suitable calibration of the calorimeter.

\section{DSC TEST ON EMULSIONS}

The test is very simple as no special treatment of the emulsion is needed. It is recommended to fill at the same time several cells with the emulsion under study. Generally, the cell volume is small (a few $\mathrm{mm}^{3}$ ) in order to assure temperature homogeneity within the sample by using scanning rates preferably up to $2.5 \mathrm{~K} / \mathrm{min}$. Nevertheless, absolute data are not required because the principle of the test proposed is based on the comparison between the thermograms. After insertion of one emulsion filled cell in the calorimeter, thermal equilibrium is waited. Afterwards, the calorimeter is programmed to be cooled down and heated between two limits of temperature. As the test is specially suitable for water-inoil emulsions, focus will be put on solidification and melting of water. Therefore, the scanning will be performed from $+20^{\circ} \mathrm{C}$ down to $-80^{\circ} \mathrm{C}$ at least, as late solidification due to undercooling and dissolved solute in water may occur. The other cells left at room temperature will be studied in the same way.

It will be also necessary to scan the thermograms of the materials of the continuous and dispersed phases separately in order to get references specially for their melting as the same behavior is expected for the emulsion.

To get information from the thermograms obtained, it is necessary to compare them to schematic ones deduced from theoretical considerations about solidification and melting of samples. These schematic and typical thermograms are described in the next section for that purpose.

\section{THEORETICAL ASPECTS AND TYPICAL THERMOGRAMS}

The principle of the method is based on the relationship between the most probable temperature of solidification $T^{*}$ of a sample and its volume $V$. Detailed theoretical aspects will not be described here as they were thoroughly developed in previous papers $[5,6]$. This paper will just remind the reader of the main points.

\subsection{Pure Compound}

We will first consider the case of a pure compound, water for instance. It is noteworthy that, whatever the sample size, ice melts at $0^{\circ} \mathrm{C}$ (except the particular case of very small submicron droplets, where capillary effects have to be considered, see Ref. [7]). On the contrary, freezing occurs at different temperatures, depending on the water sample size [5, 6]. From nucleation theory, it has been shown that the smaller 


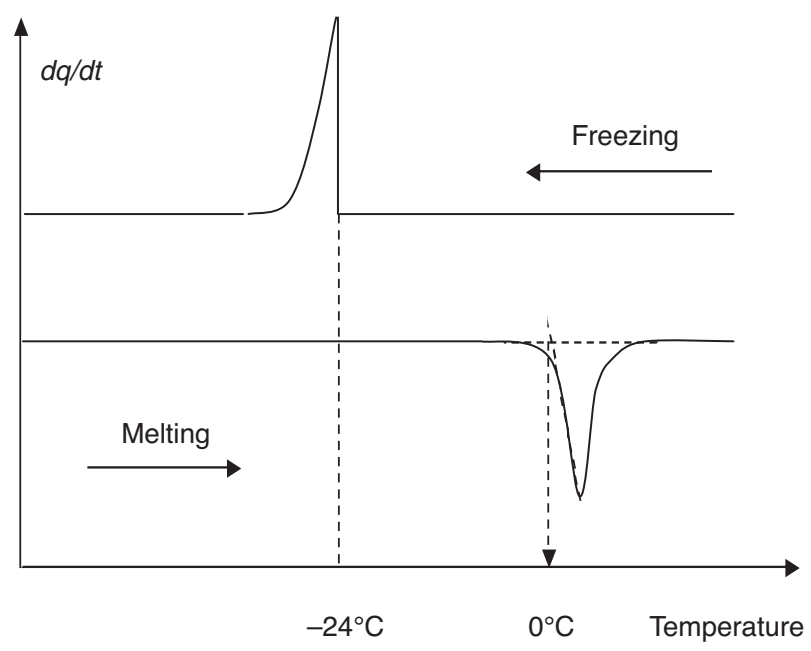

Figure 3

Cooling and heating thermograms of bulk water.

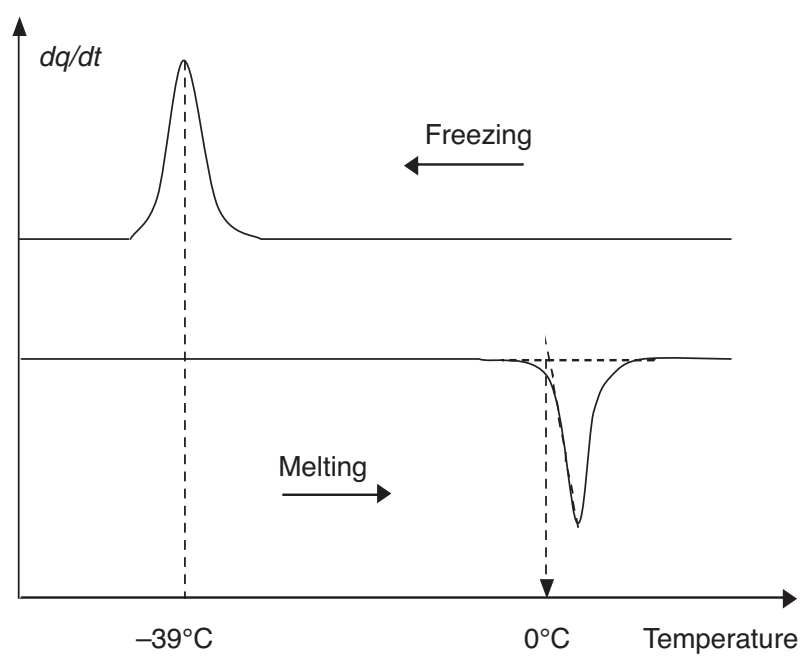

Figure 4

Cooling and heating thermograms of micro-sized droplets of water (W/O emulsion containing droplets of water of $\left.1 \mu \mathrm{m}^{3}\right)$. the volume, the lower the freezing temperature. For bulk water, freezing occurs around $-14^{\circ} \mathrm{C}$ for a volume of $1 \mathrm{~cm}^{3}$ and around $-24^{\circ} \mathrm{C}$ for a volume of $1 \mathrm{~mm}^{3}$ (Fig. 3), while for micro-sized droplets $\left(1 \mathrm{\mu m}^{3}\right)$ freezing is found around $-39^{\circ} \mathrm{C}$ (Fig. 4). Note that the temperature at which a given sample will solidify is not unique. Therefore, only a most probable temperature can be given.

Let us now describe the typical thermograms from Figures 3 and 4 . Figure 3 shows the thermogram obtained when studying the freezing of a water sample of a few milligrams. Only one germ may initiate the solidification and once nucleation occurs, the complete process of crystallization is very fast. Therefore, a significant amount of energy is released in a very short time, and that is the reason why the first part of the exothermic freezing peak is so sharp. Note that the freezing temperature is expected to vary from one sample to another, because nucleation is a stochastic phenomenon. During reheating, the melting peak is observed at $0^{\circ} \mathrm{C}$.

Figure 4 shows the thermogram obtained when studying the freezing of a monodisperse water-in-oil emulsion sample with a mean droplet size around $1 \mu \mathrm{m}^{3}$. The number of droplets dispersed in the sample of emulsion of a few milligrams is very high and sufficient to allow a statistic treatment of the various solidification temperatures of the whole droplets. The energy released during the droplets freezing is evidenced on the obtained thermogram as an exothermic peak with a quite perfect bell shape as the emulsion is monodisperse. The apex temperature of the peak may be correlated to the mean droplet size, as it will be shown later. As there is no delay in the melting phenomenon, all the droplets melt at the same temperature, i.e. $0^{\circ} \mathrm{C}$, which is the thermodynamic equilibrium temperature between ice and water.

Note that all these considerations are also valid for any pure compound, whatever its nature (mineral, organic or metal).

\subsection{Solution (Binary System)}

The presence of a solute complicates the interpretation of the thermograms but it is generally possible to understand what occurs when a solution is submitted to a steady cooling and heating by using the solid-liquid phase diagram of the binary system, as it is presented in Figure 5 in the case of water$\mathrm{NaCl}$. A complete analysis of the thermograms obtained for binary solutions in relation with binary phase diagrams can be found in references $[5,6,8]$.

We will just mention here the main lines that will help to interpret DSC thermograms.

First it is noteworthy that the presence of a solute such as $\mathrm{NaCl}$ will change the freezing and melting temperature of ice. These temperatures will be as lower as the solute concentration is higher. Depending on the concentration, the total solidification (ice + solute) may appear at the same temperature or at different temperatures if the remaining solution after ice freezing is still liquid and oversaturated with regards to salt precipitation that occurs at a lower temperature.

From a practical point of view, the typical thermogram observed in the case of a bulk solution is given in Figure 6 . During cooling, a first exothermic peak is observed at a temperature that will be lower than the one observed with pure 


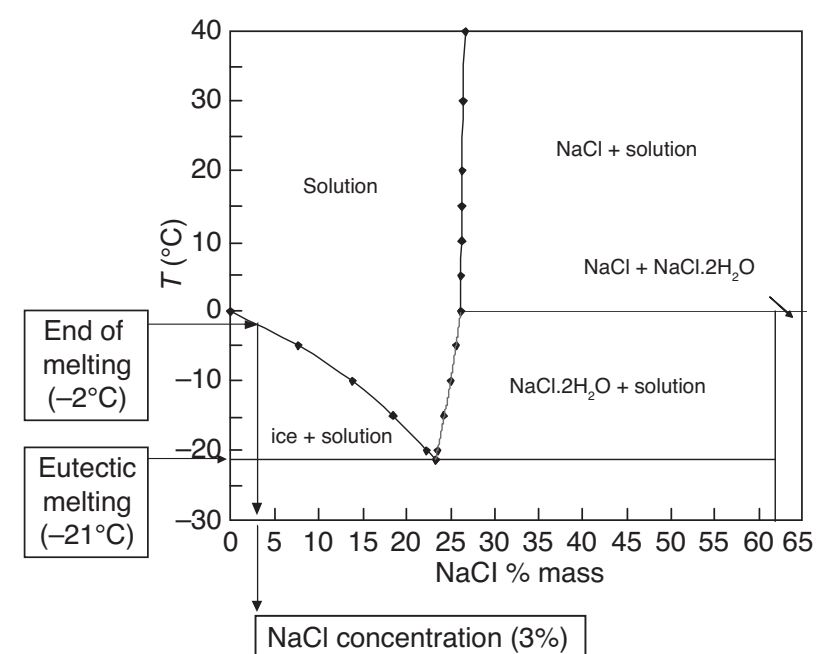

Figure 5

Phase diagram of the binary system water $+\mathrm{NaCl}$.

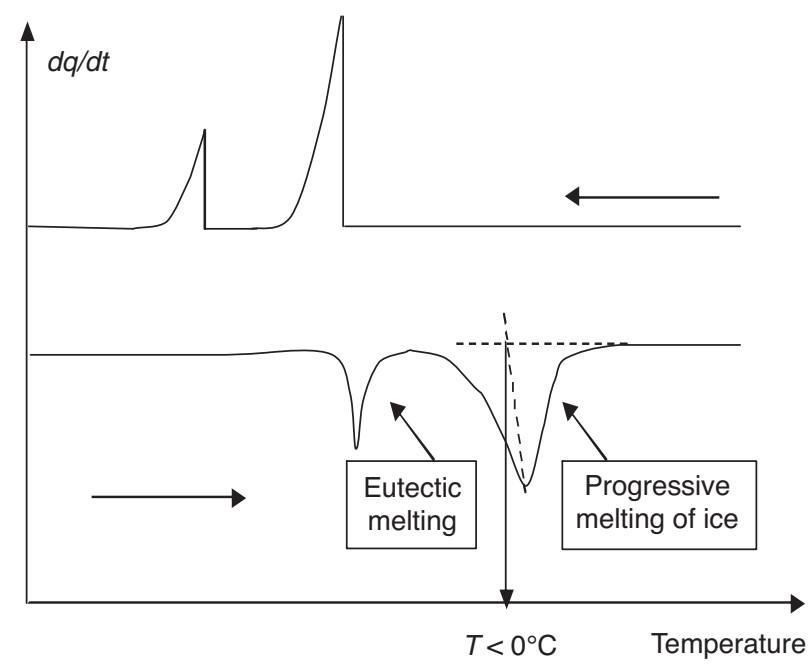

Figure 6

Cooling and heating thermograms of a bulk aqueous solution (binary system). water. If the solute concentration is not too high, it is generally followed by a second peak that corresponds to the total solidification of the remaining solution. For high concentration solutions, only one peak is obtained, corresponding to the total solidification of the system. During heating, the first endothermic peak corresponds to the eutectic melting of the binary system (for instance, $-21^{\circ} \mathrm{C}$ for water- $\mathrm{NaCl}$, see phase diagram Fig. 5). It is immediately followed by a large endothermic peak due to the progressive melting of ice. The temperature of the apex, corrected by projecting the peak top on the base line in a direction parallel with the linear portion of the eutectic melting peak (as shown in Fig. O) gives the equilibrium temperature $\left(<0^{\circ} \mathrm{C}\right.$ for an aqueous solution). The value of this equilibrium temperature may then be used to determine the concentration of the solution as shown in the phase diagram of Figure 5 in the case of $\mathrm{NaCl}$.

In the case of micron droplets of an aqueous solution dispersed in oil (W/O emulsion), we will generally observe a thermogram similar to the one presented in Figure 7 in the case of a W/O emulsion in which the aqueous phase contains $30 \mathrm{~g} / \mathrm{L}$ of $\mathrm{NaCl}$. During cooling, a unique and symmetrical exothermic peak of ice freezing is observed. The form of this peak is similar to the one of Figure 4 for a monodisperse $\mathrm{W} / \mathrm{O}$ emulsion, except that the temperature of the apex is around $-45^{\circ} \mathrm{C}$, that means slightly below the most probable temperature of ice freezing for micron droplets of pure water $\left(-39^{\circ} \mathrm{C}\right)$. This is due of course to the presence of $\mathrm{NaCl}$ in the aqueous phase. We do not observe a second peak corresponding to the total solidification while during heating, a eutectic melting and the progressive ice melting are clearly identified and prove that total solidification occurred. Several explanations can be proposed:

- ice freezing and salt precipitation are instantaneous, but it cannot be the case here because of the low salinity of the solution;

- salt precipitation occurs during the isotherm phase before reheating;

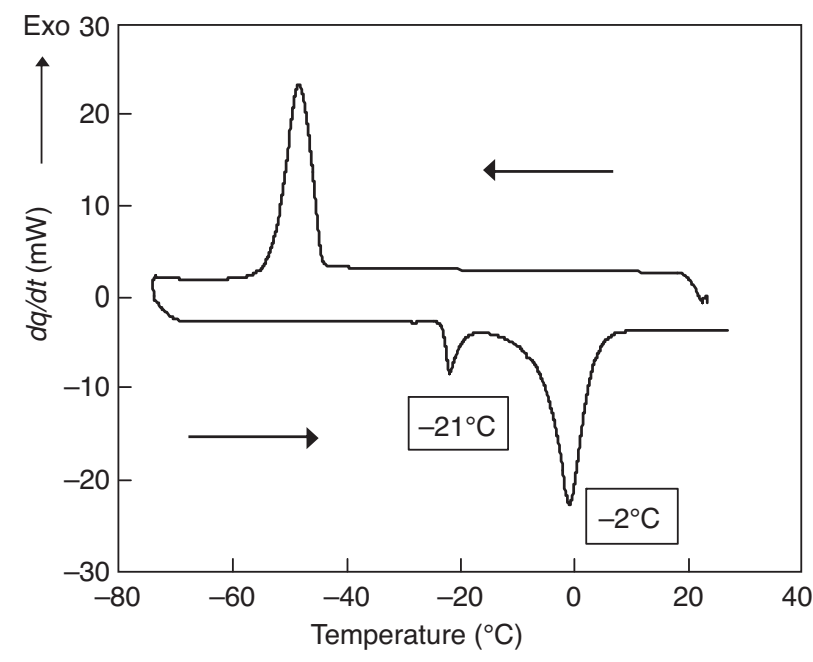

Figure 7

Cooling and heating thermograms of a W/O emulsion with $30 \mathrm{~g} / \mathrm{L}$ of $\mathrm{NaCl}$ in the water phase. 
- the peak corresponding to salt precipitation is undetectable due to the low energies involved.

It is noteworthy that in some cases, salt precipitation is avoided during the cooling phase due to the high viscosity of the oversaturated solution, but it can be observed as an exothermic peak during the heating phase. In some other cases, undercooling phenomena are so important that salt precipitation is completely impeded: during heating, only the progressive melting of ice is observed.

Nevertheless, in the case of the emulsion containing $30 \mathrm{~g} / \mathrm{L}$ of $\mathrm{NaCl}$ (Fig. 7), the heating thermogram clearly shows a peak of eutectic melting around $-21^{\circ} \mathrm{C}$ (eutectic melting of water- $\mathrm{NaCl}$, see Fig. 5), followed by a peak of progressive melting of ice ending at around $-2^{\circ} \mathrm{C}$. If this value is reported in the phase diagram of Figure 5, we obtain a $\mathrm{NaCl}$ concentration of $3 \%$ (by weight), which is in accordance with the theoretical composition of the aqueous phase of the emulsion $(30 \mathrm{~g} / \mathrm{L})$. Note that, as in the case of pure water, the melting thermogram does not depend on the sample size. Hence, the heating thermogram may be advantageously used to determine the composition of the aqueous phase.

\section{INFORMATION DEDUCED FROM DSC THERMOGRAMS}

Typical thermograms presented in the previous section are essential to get information from DSC thermograms of emulsions. Note that in order to allow an easy interpretation, it will also be necessary to analyze separately the materials of the continuous and dispersed phases to obtain thermograms of reference.

The main information that can be deduced from DSC analysis will be now reviewed.

\subsection{Type of Emulsion}

Considering an unknown emulsion composed of oil and water, it is possible to determine quite easily the nature of this emulsion. First, the separate analysis of each phase will allow us to identify, if need be, which peaks from the emulsion thermograms are related to the oil or the aqueous phase. Then, considering first the peaks related to the aqueous phase on the emulsion thermograms, we will compare them with typical thermograms previously described:

- if the form of the freezing peak is similar to the one from Figure 4, the emulsion is a water-in-oil emulsion;

- if the form of the freezing peak is similar to the one from Figure 3, the emulsion is an oil-in-water emulsion.

Note that in both cases, the same conclusion can be deduced from the analysis of the oil crystallization peak (if the oil crystallizes in the range of temperatures investigated).

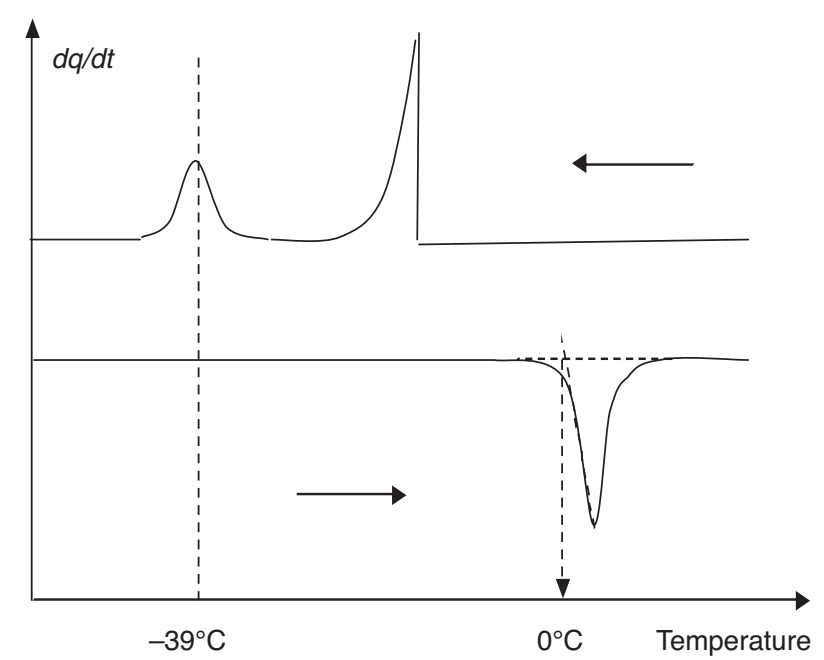

Figure 8

Cooling and heating thermograms of a multiple $\mathrm{W} / \mathrm{O} / \mathrm{W}$ emulsion.

It is interesting to mention that some more complex emulsions can also be identified. It is the case for multiple emulsions which can be of two types: water-in-oil-in-water (W/O/W) emulsions are made of oil globules containing water droplets and dispersed in water. On the contrary, oil-inwater-in-oil $(\mathrm{O} / \mathrm{W} / \mathrm{O})$ emulsions are made of water globules that contain oil droplets and dispersed in oil. These emulsions are generally formulated to trap specific substances and to control their release $[9,10]$, but they may be also spontaneously encountered during the phase inversion of a simple $\mathrm{W} / \mathrm{O}$ or $\mathrm{O} / \mathrm{W}$ emulsion, the multiple emulsion being an intermediate state. By submitting a W/O/W emulsion to a DSC test, cooling thermograms will exhibit a first ice freezing peak characteristic of the continuous aqueous phase (around $-20^{\circ} \mathrm{C}$ for pure water, see Fig. 3) followed by a second ice freezing peak characteristic of the emulsified water droplets in the oil globules (around $-39^{\circ} \mathrm{C}$ for pure water, see Fig. 4). Hence, the typical thermogram for this type of emulsion is the one of Figure 8, if we assume that the oil phase does not crystallize in this range of temperature. Concerning the $\mathrm{O} / \mathrm{W} / \mathrm{O}$ emulsion, if the oil does not crystallize, we should observe a cooling thermogram similar to the one of a simple W/O emulsion (Fig. 4), but shifted to higher temperatures $\left(>-39^{\circ} \mathrm{C}\right.$ for pure water globules), due to the fact that the globules of water are much larger than $1 \mu \mathrm{m}$.

Finally, the last type of emulsion that can be analyzed by DSC are mixed emulsions. Mixed emulsions are so called because they are obtained from the mixing of two simple emulsions that differ by the compositions of the dispersed phases. The mixing has to be done gently in order to avoid 
coalescence. Due to the difference in composition of the droplets, some mass transfer may occur between them. This phenomenon is called composition ripening (in analogy with Ostwald ripening for simple emulsions) as it leads to droplets of homogeneous composition [11-13]. It has been proposed as a way to obtain size-controlled droplets by using an adapted formulation of the father-mother emulsions [11]. The mixed emulsion being the result of the addition of two simple emulsions, the resulting thermogram will be also, at the very beginning, composed of the addition of the two thermograms corresponding to each separate simple emulsions. Obviously, as mass transfer will occur with time due to the difference of composition between droplets, DSC analyses performed at different ageing of the mixed emulsion will be an interesting tool to follow the emulsion evolution. In fact, the mass transfer will be evidenced by a shift in the crystallization peaks corresponding to each "primary" emulsion. Several examples can be found in references $[6,14]$.

\subsection{Amount of Water}

As previously mentioned, the energy of a thermal phenomenon can be measured by the surface area of the corresponding peak. Knowing the value of the latent heat of melting of ice ( $80 \mathrm{cal} / \mathrm{g}$ for pure water), it is then quite easy to quantify the amount of water in the emulsion by integrating the melting peak of ice. The same method can be used for any other pure compound (oil, metal, organic compound, etc.). For aqueous solutions or complex oily systems, it is necessary to determine the melting energy by performing a separate DSC analysis of the bulk compound.

\subsection{Presence of a Solute}

If a solute is present in the water phase, the temperature of melting will be shifted towards lower temperatures $\left(<0^{\circ} \mathrm{C}\right)$. The higher the solute concentration, the lower the melting temperature. If the binary phase diagram is available, it is possible to determine the concentration of the solute in the aqueous phase, as it has been explained in the previous section dealing with solutions (binary systems).

\subsection{Stability}

The DSC analysis of an emulsion at different times or at different levels in the test tube (for example bottom, middle and top) may give precious information on the stability of the system. For a stable W/O emulsion, the cooling and heating thermograms will be similar to the thermograms presented in Figure 4. If the emulsion is totally broken (i.e. the oil and water phases are separated), the thermograms will be those from Figure 3 (bulk water). For all the intermediate situations, we will observe cooling thermograms with one or

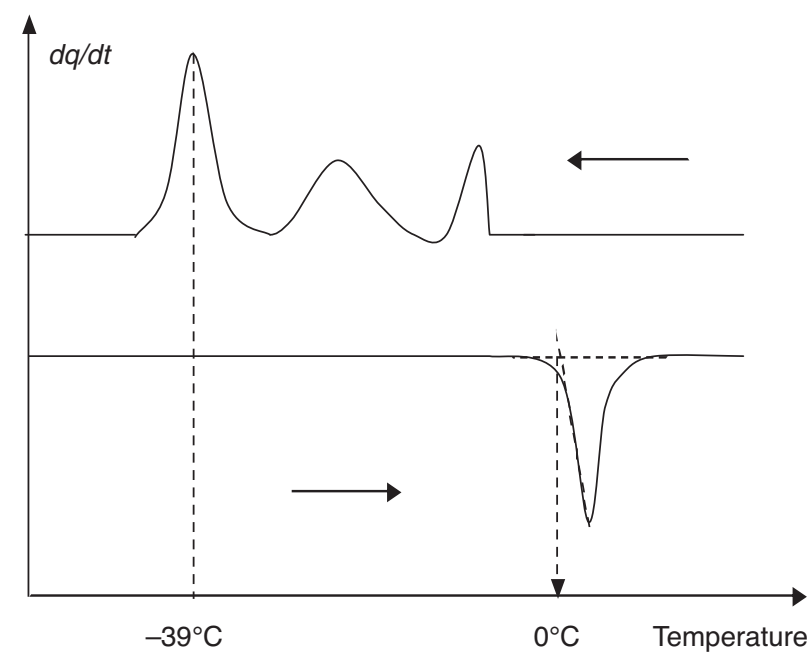

Figure 9

Cooling and heating thermograms of a polydisperse W/O emulsion.

several exothermic peaks located between $-39^{\circ} \mathrm{C}$ and $0^{\circ} \mathrm{C}$, the higher the temperature, the larger the droplet size.

For instance, a destabilized polydisperse W/O emulsion showing a population of droplets with very small droplets, medium size droplets $(50-100 \mu \mathrm{m})$ and free water will be characterized by the typical thermograms given in Figure 9. Hence, it is quite easy to follow the destabilization of a W/O emulsion due to coalescence through the evolution of the ice freezing peaks. It is also possible to have an idea of the destabilization due to sedimentation (without coalescence) by following the water content of the emulsion through the integration of the ice melting peak, as previously explained. If water droplets tend to sediment, the water content in the bottom of the emulsion sample will be higher than on the top.

\subsection{Droplet Size}

Microcalorimetry may provide useful qualitative information about the granulometry of emulsions. Of course, one may differentiate a bulk phase from a dispersed one or characterize the degree of polydispersity of an emulsion as shown previously. Emulsion granulometry may be modified during time, temperature cycles, crystallizations, mechanical stress or chemical reactivity for example. Qualitative information about alterations of emulsions may then be obtained by direct comparison of thermograms.

But it is noteworthy that quantitative information on the granulometry of emulsions may also be deduced from data obtained during crystallization and in fact nucleation inside droplets. Two possibilities exist. First, one may derive an 
equation between the crystallization temperature of a droplet and its size from theoretical consideration, as it has been described in reference [15]. This theoretical approach is based on the fact that to induce freezing, the formation of an ice germ is required. Due to capillary phenomena, it is possible to demonstrate that the relation between the water droplet radius $R$ and the freezing temperature $T$ is given by the following equation:

$$
R^{3}=0.69 \frac{3 \dot{T}}{4 \pi \int_{T_{f}}^{T} A \cdot \exp \left[-\frac{16 \pi \gamma^{3} V_{s}}{3 L_{f}^{2} \ln ^{2}\left(T / T_{f}\right)} \frac{1}{k T}\right] d T}
$$

where $\dot{T}\left(\mathrm{~K} . \mathrm{s}^{-1}\right)$ is the scanning rate, $A\left(\mathrm{~s}^{-1} \cdot \mathrm{m}^{-3}\right)$ is the pre exponential factor in the expression of the nucleation rate, $k$ (N.m.K $\left.{ }^{-1}\right)$ is the Boltzman constant, $\gamma\left(\mathrm{N} . \mathrm{m}^{-1}\right)$ is the interfacial tension between water and the ice germ, $V_{s}\left(\mathrm{~m}^{3} \cdot \mathrm{mole}^{-1}\right)$ is the molar volume of the germ, $L_{f}\left(\right.$ N.m.mole $\left.{ }^{-1}\right)$ is the molar melting heat and $T_{f}(\mathrm{~K})$ is the melting temperature.

So it is clear from Equation (4) that the relation between $R$ and $T$ is far from direct, and the difficulty is essentially due to the impossibility to determine $\gamma$ from an experimental point of view. That is the reason why it is preferable to determine an empirical correlation between $R$ and $T$ by comparing the most probable freezing temperatures obtained from DSC thermal analysis and the mean droplet size obtained by another analytical technique (optical microscopy for instance).

Examples of this type of correlation can be found in References [14, 15].

\section{APPLICATIONS}

Applications of DSC for characterizing complex emulsified systems are described in several papers [6, 14-21]. We will present here recent examples related to the case of complex emulsions encountered in the oilfield industry.

\subsection{Crude Oil Emulsions}

The formation of stable water-in-crude oil emulsions is frequently encountered during oil production, mainly due to high shear rates and zones of turbulence that prevail at the wellhead in the choke valve. These complex and generally viscous systems significantly increase the technical problems related to oil-water separation in production surface facilities [1]. These emulsions can be very stable due to the presence of polar compounds such as asphaltenes and resins that play the role of "natural emulsifiers" and also to the presence of many types of fine solids (crystallized waxes, clays, scales, etc.) that help in the formation of resistant films at the crude oil/water interface.
Effective separation of crude oil and water is an essential operation to ensure not only the quality of crude oil but also the quality of separated water phase at the lowest cost. Earlier studies [22, 23] have shown the importance of emulsion characteristics on the performance and optimization of oil-water separation. Recently, in the framework of a joint study between IFP and Saudi Aramco, a strict and rigorous methodology was applied to gather information about the behavior and composition of Saudi Aramco emulsion samples collected from several Gas Oil Separation Plants [20, 21]. The samples were first separated to identify the amount of separated oil, water and residual emulsion. Each phase was then analyzed separately. Bulk properties (viscosity, density) as well as the chemical composition of crude oil were determined. Salinity of the separated water in terms of ionic composition was measured when possible or assessed by DSC in other cases. The residual emulsions were characterized using several techniques such as Karl Fischer titration to determine the water content, and DSC (Differential Scanning Calorimetry), optical microscopy and/or cryoSEM to assess the size and polydispersity of the dispersed droplets.

As an example, Figures 10a and 11a show DSC thermograms obtained during the successive freezing-melting cycles performed on two different residual emulsions (E6 and E8), i.e. the emulsions obtained after separation of the free oil and free water phases. DSC analyses were also performed on the separated oil and water phase in order to get thermograms of reference for each phase. It was checked that the oil did not crystallize in the range of temperatures investigated. DSC thermogram from emulsion E6 (Fig. 10a) shows a single regular peak of ice freezing during cooling, with a bell shape, at around $-70^{\circ} \mathrm{C}$. This signal is characteristic of a fine and monodisperse emulsion. The very low temperature is far from the one expected with pure water $\left(-39^{\circ} \mathrm{C}\right)$ and it is due to the high salinity of the water phase, which may be assessed through the melting peak obtained during heating. During melting, we observe an irregular peak which is in fact composed of an eutectic peak at around $-23^{\circ} \mathrm{C}$ (very close to the eutectic melting temperature of the binary system water + $\mathrm{NaCl}$ ) immediately followed by the progressive melting of ice. This second peak appears as a shoulder after the eutectic melting at a temperature of around $-19^{\circ} \mathrm{C}$. If we assume that the major salt of the aqueous solution is $\mathrm{NaCl}$, which is generally the case in oilfield emulsions, we can determine the approximate concentration of the solution by reporting this temperature on the phase diagram from Figure 5. One obtains an approximate concentration of $\mathrm{NaCl}$ in the solution of $21.5 \%$. By integrating these melting peaks and using the melting energy determined from the DSC analysis of the corresponding bulk water phase, it is also possible to measure the aqueous phase content in the emulsion (62\%).

For emulsion E8 (Fig. 11a), several exothermic peaks are observed during cooling. The main peak around $-50^{\circ} \mathrm{C}$ is 

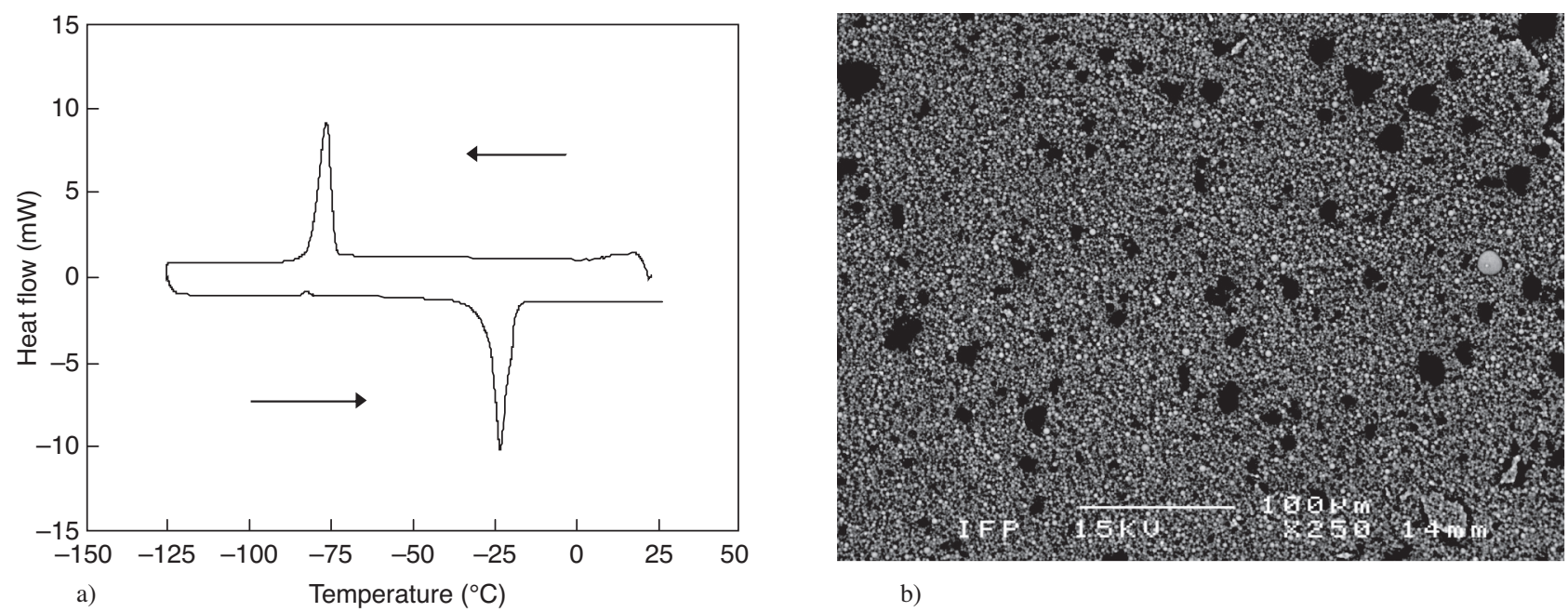

Figure 10

a) Cooling and heating thermograms of emulsion E6,

b) Cryo-SEM photo of emulsion E6.
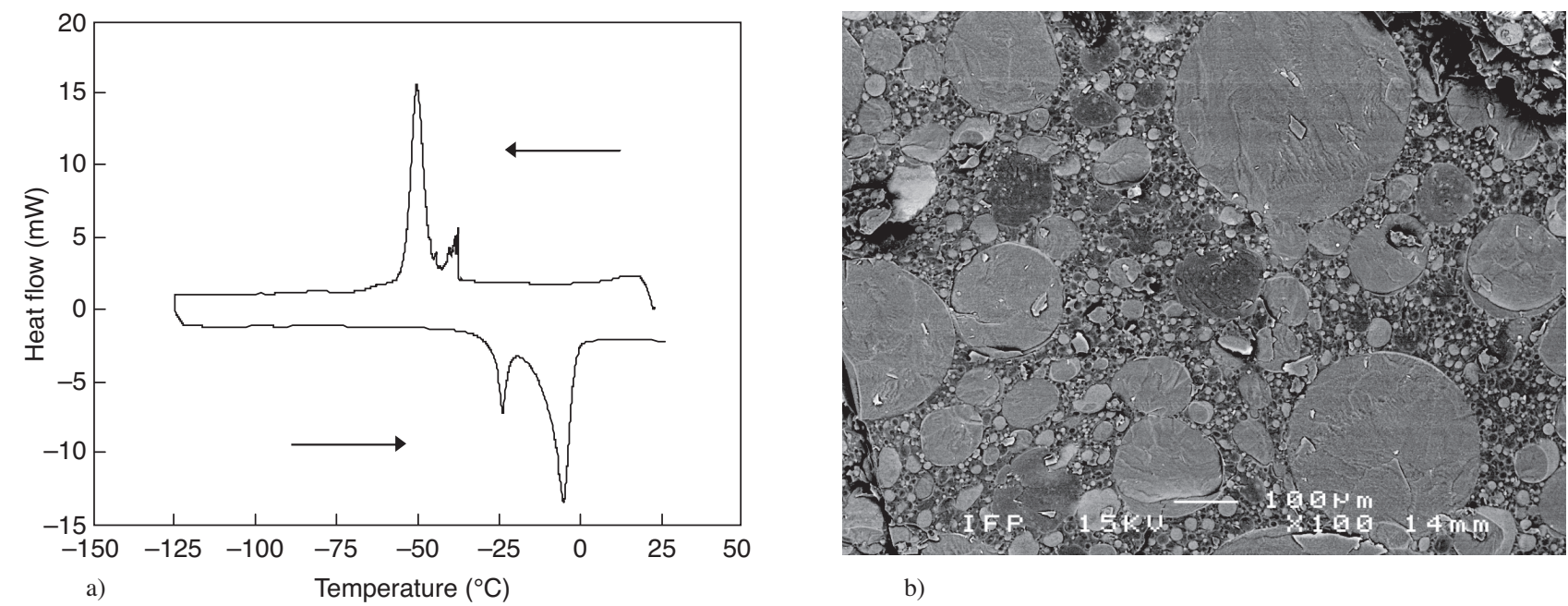

b)

Figure 11

a) Cooling and heating thermograms of emulsion E8,

b) Cryo-SEM photo of emulsion E8.

characteristic of finely emulsified water droplets. Several sharp peaks are observed at higher temperatures, proving that large droplets are also present in this emulsion. During the heating phase, a first endothermic peak is observed at $-23^{\circ} \mathrm{C}$, as in the case of emulsion E6, which corresponds approximately to the eutectic melting of water $+\mathrm{NaCl}$. This peak is then followed by the peak of progressive melting of ice that ends around $-4^{\circ} \mathrm{C}$. By assuming that the major salt is $\mathrm{NaCl}$, the concentration deduced from the binary phase diagram of Figure 5 is around $7 \%$.
To confirm this DSC characterization of emulsions, microscopic analyses were performed with cryo-SEM (Figs. 10b, 11b). Figure 10b (emulsion E6) shows clearly a fine and monodisperse emulsion (mean droplet diameter is around 2 microns). On the contrary, Figure 11b (emulsion E8) shows a characteristic polydisperse emulsion, composed of very small, medium and large droplets (4 to $600 \mu \mathrm{m})$. Karl Fischer titrations were also performed to determine the water content in emulsions. The results obtained are 58\% for emulsion E6, which is very close to the value obtained by DSC 
(62\%), and 55\% for emulsion E8, which differs from the DSC data. The differences in values for sample 8 can be explained by the polydispersity of the emulsion concerned. In fact, when emulsions are polydisperse, it is quite difficult to get a representative sample for DSC, as the amount required is very small (few $\mathrm{mg}$ ), compared to the amount required for Karl Fischer (200-400 mg). Finally, data concerning the total salinity of aqueous phases were provided by Saudi Aramco. These data are of the same order of magnitude as the data obtained from DSC analyses. All the results concerning the characterization of emulsions are gathered in Table 1.

TABLE 1

Characterization of emulsions

Comparison between DSC and other analytical techniques

\begin{tabular}{l|c|c}
\hline & Emulsion E6 & Emulsion E8 \\
\hline $\begin{array}{l}\text { Type of emulsion from } \\
\text { DSC analysis }\end{array}$ & W/O monodisperse & W/O polydisperse \\
\hline Droplet size from cryo-SEM & $2 \mu \mathrm{m}$ & 4 to $600 \mu \mathrm{m}$ \\
\hline Water content from DSC (\% wt) & $62 \%$ & $78 \%$ \\
\hline $\begin{array}{l}\text { Water content from (\% wt) } \\
\text { Karl Fischer titration }\end{array}$ & $58 \%$ & $55 \%$ \\
\hline Salinity from DSC (\% wt NaCl) & $21 \%$ & $7 \%$ \\
\hline Salinity from oilfield data & $200 \mathrm{~g} / \mathrm{L}$ & $66 \mathrm{~g} / \mathrm{L}$ \\
\hline
\end{tabular}

Consequently, DSC appears as a very useful and rapid technique to rapidly get considerable information about emulsion behaviour (nature and polydispersity), approximate water content and salinity.

\subsection{Oil-Based Mud Systems}

The success of any well-drilling operation depends on many factors, one of the more important being the drilling fluid. The fluid performs a variety of functions that influence the drilling rate, the efficiency, the safety and of course the cost of the operation [24]. Drilling fluids are generally composed of liquids (water or oils) and suspended, finely divided solids of different nature. They are classified as to the nature of the continuous phase: gas, water or oil. Within each broad classification are divisions based on composition or chemistry of the fluid or the dispersed phase. For many years, oil-based muds have proved to be the best performance and cost effective fluids in difficult drilling situations. Typical muds are water-in-oil emulsions with an aqueous phase (brine) varying from 5 to 40 per cent. These reverse emulsions mainly contain emulsifiers for improving the emulsion stability, organophilic clays for controlling rheological properties, especially thixotropy, and weighting agents, such as calcium carbonate or barium sulfate, to adjust the fluid density.
Considering the specific conditions of use of oil-based muds (high pressure/high temperature), the characterization of their stability, especially with temperature, is essential. But the complicated nature of these drilling fluids makes these studies very difficult to achieve. Stability is therefore generally assessed from simple bottle tests and empirical standardized tests, such as electrical stability measurements. Classical techniques for the determination of water droplet size distribution cannot be applied because of the great amount of solids contained in drilling muds. With bottle tests, the only evidence of destabilization is given by the kinetics of clarification of the supernatant phase. Considering that all the solids as well as water droplets tend to sediment, it is then quite impossible to observe the coalescence of liquid droplets. It is therefore difficult to determine if destabilization is simply due to flocculation and sedimentation of particles and droplets or if both liquid phases are completely separated by coalescence phenomena. That is the reason why DSC was used to characterize the stability of oil based systems and it was a precious tool to develop new emulsifiers adapted to high pressure and high temperature conditions of drilling [16] or to deep offshore drilling when the formation of hydrates has to be avoided [18]. Figure 12 shows the DSC thermograms obtained during the cooling and heating of an oilbased drilling fluid formulated with an experimental emulsifying system. During cooling, a unique peak of ice freezing is observed at $-60^{\circ} \mathrm{C}$. Its form is characteristic of a fine emulsion. This low temperature of $-60^{\circ} \mathrm{C}$ is due to the composition of the aqueous phase which is in fact a brine with $15 \%$ wt. of $\mathrm{CaCl}_{2}$. During heating, no eutectic melting is observed, surely because of undercooling phenomena related

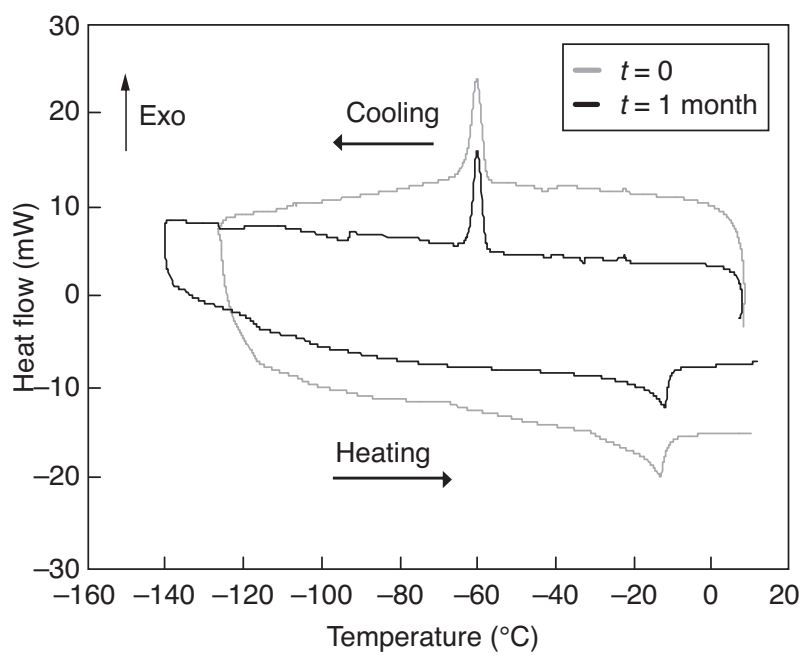

Figure 12

Cooling and heating thermograms of an oil-based drilling fluid before $(t=0)$ and after ageing ( $t=1$ month). 


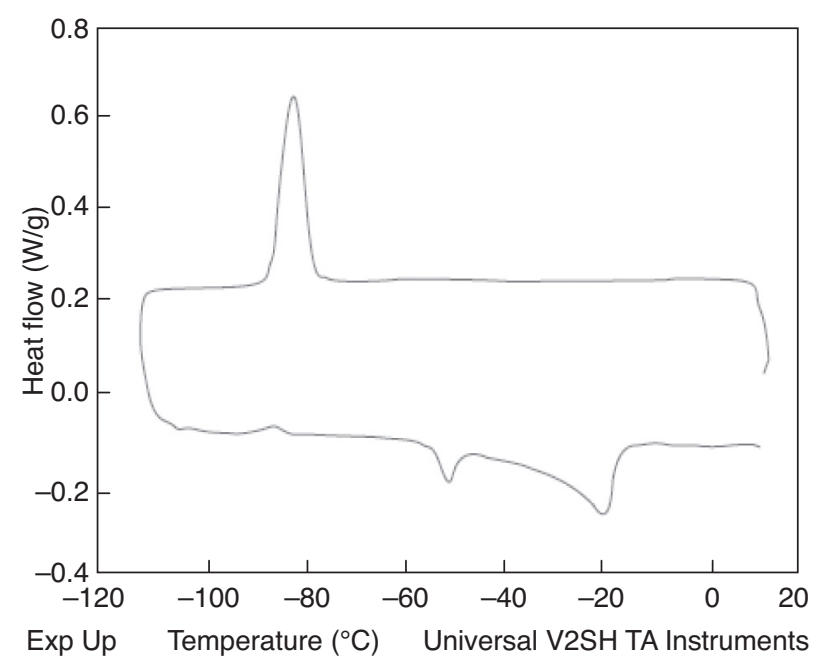

a)

Figure 13

a) Cooling and heating thermograms of a mud filtercake,

b) Cryo-SEM photo of the cake.

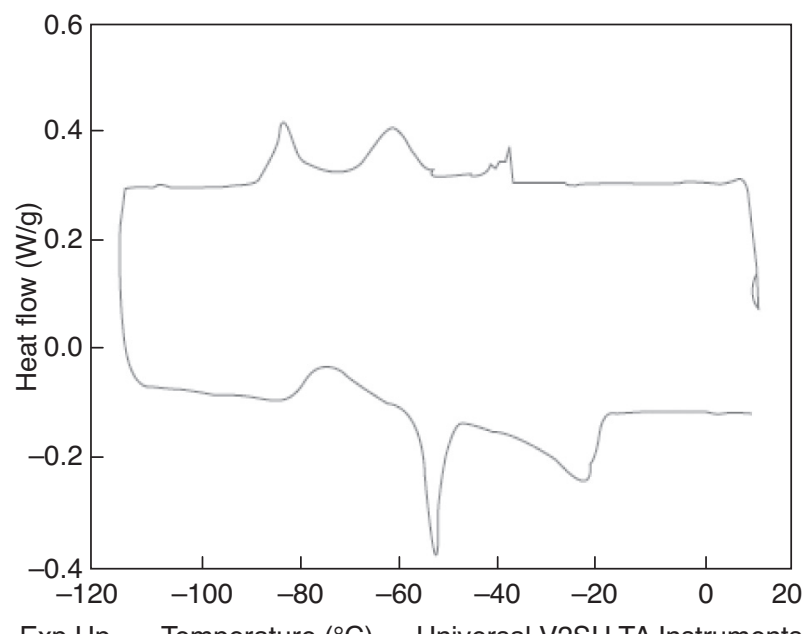

Exp Up Temperature $\left({ }^{\circ} \mathrm{C}\right) \quad$ Universal V2SH TA Instruments a)

Figure 14

a) Cooling and heating thermograms of a mud filtercake treated with a surfactant,

b) Cryo-SEM photo of the cake.

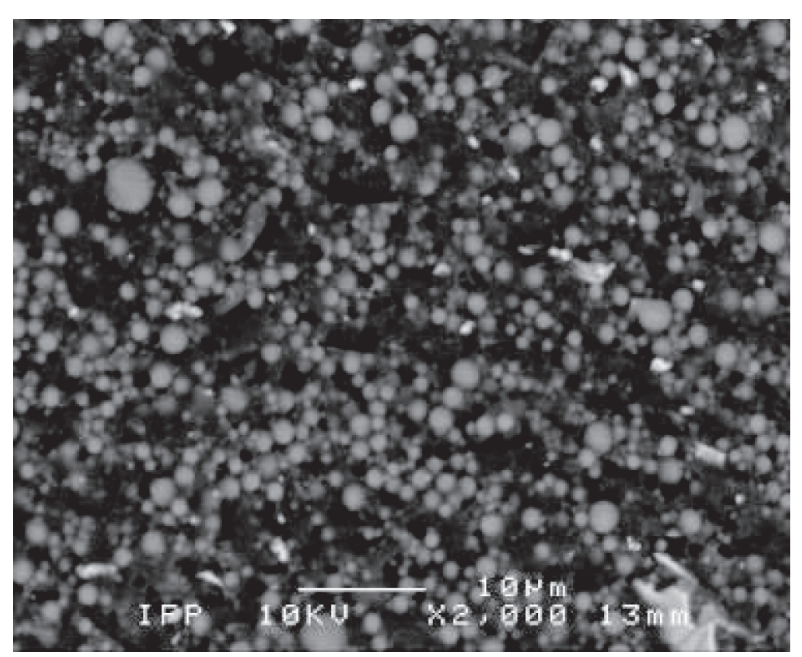

b)

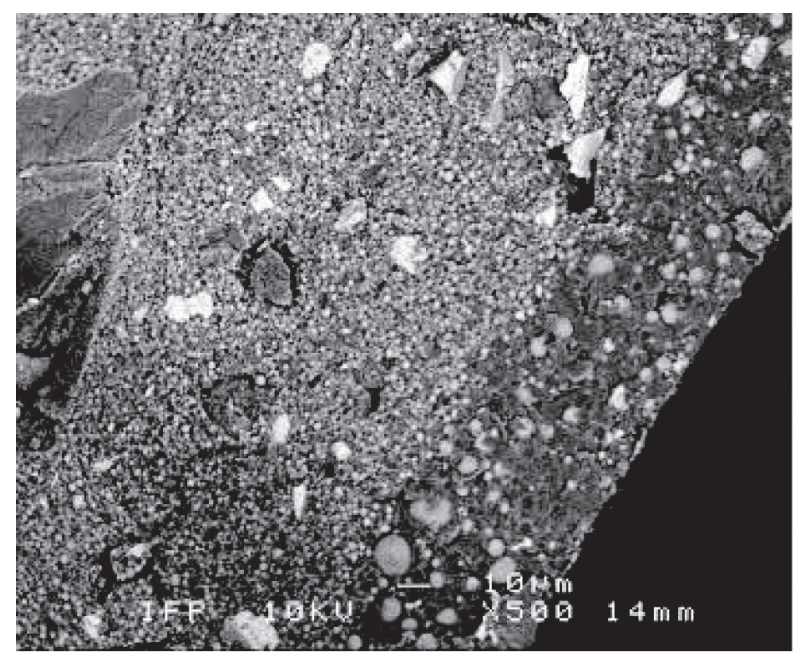

b) to the high salinity of the brine. But a peak of progressive melting of ice is observed, that ends at about $-12^{\circ} \mathrm{C}$, which corresponds to the liquid/solid equilibrium temperature of a $15 \%$ wt. $\mathrm{CaCl}_{2}$ solution. After one month of ageing, the DSC thermograms are perfectly superimposed with those of the initial emulsion, which proves that this emulsion is stable over this period of time.

Another study performed in IFP concerned the breaking of oil-based mud filtercakes. Actually, oil-based muds are used to drill complex wells. Even if they are less damaging than water-based muds, they may induce severe damage that decreases reservoir overall productivity. During drilling, mud solid parts and brine droplets tend to form a filter cake along the wellbore through filtration, while the oil phase tends to leak off into the formation. Clean-up process is then necessary to restore the productive zone to a near-natural state before production. Chemical treatment is often used to break filtercake and to wash-off damaged zone around the wellbore, so that the formation could recover its oil transfer properties. We have therefore developed a methodology using 
DSC in order to select an organic-based surfactant system able to break the cake formed by filtration of a given oilbased mud system. The demulsifying formulation should bother interface surfactants stabilizing effect and allow water droplets coalescence inside the cake. Through breaking emulsion inside the cake, surfactants should decrease cake cohesion and bore adherence.

The filtercake obtained after filtration of an oil-based mud on a filter paper $\left(80^{\circ} \mathrm{C}, 35\right.$ bar) was first characterized before treatment with the surfactant. The cake thermogram (Fig. 13a) is similar to the mud thermogram. It is characteristic of a stable emulsion. On solidification curve, a single bell-shaped peak is located around $-80^{\circ} \mathrm{C}$, which indicates solidification of tiny water droplets. The melting curve shows a small eutectic peak at $-52^{\circ} \mathrm{C}$ (eutectic melting temperature of the water $+\mathrm{CaCl}_{2}$ binary system) and progressive ice melting around $-20^{\circ} \mathrm{C}$. This shows that emulsion inside the filtercake is very fine and stable. Cryo-SEM observation reinforces DSC analysis: cake emulsion seems to be identical to mud emulsion, but more concentrated (Fig. 13b).

An efficient surfactant system selected from bottle tests has been tested on three filtercakes, coming from three different mud formulations. Solidification thermograms of the cakes treated with the surfactant are similar: free water peak is located around $-35^{\circ} \mathrm{C}$ on the cooling curve. Signal magnitude increases with contact time and temperature. Moreover solidification signal of emulsified water changes from a single-bell shaped peak to a series of peaks, which characterize emulsion polydispersity (Fig. 14a). Cryo-SEM analysis reveals emulsion breaking (bigger droplet size) in the upper third of the cake (Fig. 14b).

\section{CONCLUSION}

The characterization of the stability of complicated emulsions like crude oil emulsions or drilling fluids is always a great challenge. Differential Scanning Calorimetry can be definitely considered as an essential and versatile technique that allows one to work directly on complex emulsified systems. It is rapid, easy and precise, and requires only small amounts of emulsions. The test is easy to set up. It consists of submitting an emulsion sample, that does not need to be diluted, to a regular cooling and melting. It is very important to note that both thermograms of cooling and heating are needed to give a reliable interpretation. Schematic thermograms have been drawn to give a help to the user willing to characterize different types of emulsions. Practical examples show how to use them and how it is possible to get information about the changes occurring within emulsions versus time. DSC is particularly suitable for obtaining a great amount of information about emulsion type, composition of dispersed and continuous phases as well as polydispersity of the emulsion. However, each technique has its limitation, and the main drawback of DSC is certainly the sample size (a few tens of $\mathrm{mg}$ ), which makes difficult the study of very unstable emulsions. Nevertheless, it is always recommended to use if possible at least two different techniques to characterize the stability of emulsions.

\section{REFERENCES}

1 Schramm L.L. (1992) Emulsions-Fundamentals and Applications in the Petroleum Industry. Washington, DC: Advances in Chemistry Series 231, American Chemical Society, pp. 1-49.

2 Bridié A.L., Wanders T.H., Zegveld W., Van der Heidge H.B. (1980) Formation, Prevention and Breaking of Seawater in Crude Oil Emulsions 'Chocolate Mousses', Mar. Pollut. Bull. 11, 343-348.

3 Lissant K.J. (1983) Demulsification-Industrial Applications, Marcel Dekker, New York, pp. 105-132.

4 Gray A.P. (1968) in Analytical Calorimetry, Porter R.J., Johnson J.F. (eds.), Plenum Press New York, Vol. 1, p. 209.

5 Clausse D. (1985) in Encyclopedia of Emulsion Technology. Vol. 2: Applications, Becher P. (ed.), Marcel Dekker, New-York and Basel, pp. 77-157.

6 Dalmazzone C., Clausse D. (2001) in Encyclopedic Handbook of Emulsion Technology, Sjöblom J. (ed.), Marcel Dekker, New York, Chap. 14.

7 Brun M., Lallemand A., Quinson J.-F., Eyraud C. (1977) A new method for the simultaneous determination of the size and shape of pores: the thermoporometry, Thermochim. Acta 21, 59-88.

8 Clausse D. (1998) Thermal behaviour of emulsions studied by differential scanning calorimetry, J. Therm. Anal. 51, 191-201.

9 Raynal S., Pezron I., Potier L., Clausse D., Grossiord J.L., Seiller M. (1994) Study by differential scanning calorimetry, rheometry and electroconductimetry of mass transfers at subambient and ambient temperatures in multiple w/o/w emulsions entrapping $\mathrm{MgSO}_{4}$, Colloid. Surface. A 91, 191-205.

10 Potier L., Raynal S., Seiller M., Grossiord J.L., Clausse D. (1992) Study of state transitions within multiple W/O/W emulsions using calorimetry (DSC), Thermochim. Acta 204, 145-155.

11 Binks B.P., Clint J.H., Fletcher P.D.I. , Rippon S., Lubetkin S.D., Mulqueen P.J. (1999) Kinetics of swelling of oil-in-water emulsions stabilized by different surfactants, Langmuir 15, 44954501.

12 Taisne L., Walstra P., Cabane B. (1996) Transfer of Oil between Emulsion Droplets, J. Colloid Interf. Sci. B 184, 378-390.

13 McClements D., Dungan S. (1993) Factors that affect the rate of oil exchange between oil-in-water emulsion droplets stabilized by a nonionic surfactant: droplet size, surfactant concentration, and ionic strength, J. Phys. Chem. 97, 7304-7308.

14 Clausse D., Gomez F., Pezron I., Komunjer L., Dalmazzone C. (2005) Morphology Characterization of Emulsions by Differential Scanning Calorimetry, Adv. Colloid Interfac. 117, 59-74.

15 Clausse D., Gomez F., Dalmazzone C., Noik C. (2005) A method for the characterization of emulsions: Thermogranulometry - Application to water-in-oil emulsion, J. Colloid Interf. Sci. 287, 694-703. 
16 Evans N., Langlois B., Audibert-Hayet A., Dalmazzone C., Deballe E. (2000) High performance emulsifiers for synthetic based muds, Proceedings of SPE 2000 ATCE, Dallas, Tx, USA, 1-4 Oct. 2000, SPE paper No. 63101, pp. 513-523.

17 Giard-Blanchard C., Audibert-Hayet A., Dalmazzone C. (2001) Development and Application of Surfactant-Based Systems for Treatment of Wells Drilled with OBM, Proceedings SPE European Formation Damage Conference, The Hague, The Netherlands, 21-22 May 2001, SPE paper No. 68960.

18 Audibert A., Dalmazzone C., Dalmazzone D., Dewattines C. (2004) Special non polluting emulsifier for non aqueous drillings fluids in deep offshore drilling, Proceedings SPE ATCE 2004, Houston, Tx, USA, 26-29 Sept. 2004, SPE Paper No. 89989.

19 Noik C., Dalmazzone C., Goulay C., Glenat P. (2005) Characterization and Emulsion Behavior of Athabasca Extra Heavy Oil Produced by SAGD, Proceedings International Thermal Operations and Heavy Oil Symposium, Calgary, Canada, 1-3 Nov 2005, SPE paper No. 97748.

20 Al-Ghamdi A.M., Noïk C., Dalmazzone C., Kokal S. (2007) Experimental Investigation of Emulsions Stability in GOSPs -
Part I: Analyses of Separated Phases, Proceedings SPE International Symposium on Oilfield Chemistry, Houston, Tx, USA, 26 Feb.-2 March 2007, SPE paper No. 106128.

21 Al-Ghamdi A.M., Noïk C., Dalmazzone C., Kokal S. (2007) Experimental Investigation of Emulsions Stability in GOSPs Part II: Emulsion Behavior, Proceedings SPE ATCE 2007, Anaheim, Ca, USA, 11-14 Nov. 2007, SPE Paper No. 109888.

22 Kokal S.L., Al-Ghamdi A.M. (2006) Performance Appraisals of Gas Oil Separation Plants, Proceedings SPE ATCE, San Antonio, Tx, USA, 24-27 September 2006, SPE Paper No. 102854.

23 Kokal S.L., Al-Ghamdi A.M. (2006) An Investigative Study of Potential Emulsion Problems Before Field Development, Proceedings SPE ATCE, San Antonio, Tx, USA, 24-27 September 2006, SPE paper No. 102856.

24 Nguyen J.-P. (1993) Drilling, Technip Editions, Paris, pp. 115138.

Final manuscript received in July 2008 Published online in October 2008 or distributed for profit or commercial advantage and that copies bear this notice and the full citation on the first page. Copyrights for components of this work owned by others than IFP must be honored. Abstracting with credit is permitted. To copy otherwise, to republish, to post on servers, or to redistribute to lists, requires prior specific permission and/or a fee: Request permission from Documentation, Institut français du pétrole, fax. +33147527078 , or revueogst@ifp.fr. 